\title{
Evolution and diversity of the angiosperm anther: trends in function and development
}

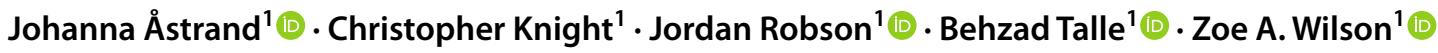

Received: 11 February 2021 / Accepted: 28 May 2021 / Published online: 26 June 2021

(c) The Author(s) 2021, corrected publication 2021

\begin{abstract}
Key message Anther development and dehiscence is considered from an evolutionary perspective to identify drivers for differentiation, functional conservation and to identify key questions for future male reproduction research. Abstract Development of viable pollen and its timely release from the anther are essential for fertilisation of angiosperm flowers. The formation and subsequent dehiscence of the anther are under tight regulatory control, and these processes are remarkably conserved throughout the diverse families of the angiosperm clade. Anther development is a complex process, which requires timely formation and communication between the multiple somatic anther cell layers (the epidermis, endothecium, middle layer and tapetum) and the developing pollen. These layers go through regulated development and selective degeneration to facilitate the formation and ultimate release of the pollen grains. Insight into the evolution and divergence of anther development and dehiscence, especially between monocots and dicots, is driving greater understanding of the male reproductive process and increased, resilient crop yields. This review focuses on anther structure from an evolutionary perspective by highlighting their diversity across plant species. We summarise new findings that illustrate the complexities of anther development and evaluate how they challenge established models of anther form and function, and how they may help to deliver future sustainable crop yields.
\end{abstract}

Keywords Anther evolution · Pollen development $\cdot$ Anther dehiscence $\cdot$ Microsporogenesis $\cdot$ Anther wall formation

Communicated by Frederic Berger.

A contribution to the special issue 'Evolution of Plant Reproduction'.

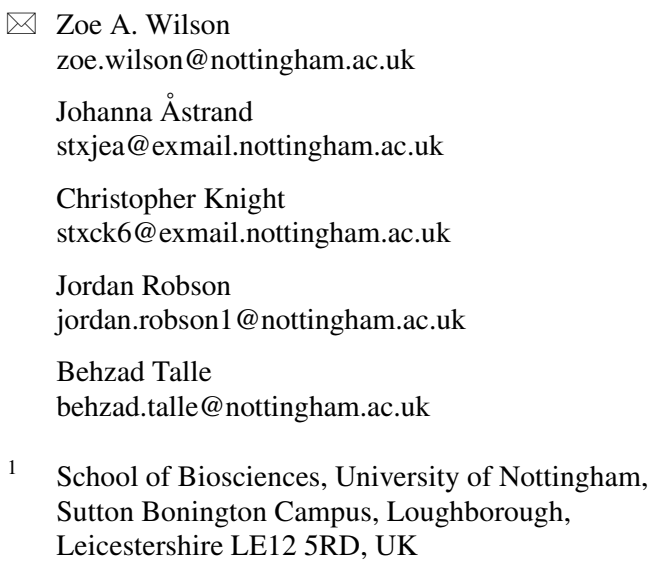

\section{Introduction}

The anther is the pollen producing part of the stamen, which is supported by a stalk-like filament, and together, they make up the male reproductive structure of the angiosperm flower. Throughout the evolution of the angiosperms, the stamen has undergone a variety of adaptations to enhance reproductive success (Doyle 2012; Endress and Doyle 2009; Sauquet et al. 2017). The range of complexity in anther wall formation, filament attachment and anther dehiscence emphasise the scale of anther adaptability (Endress 1996). The differentiation and formation of the anther walls enclosing the developing microsporangia are still poorly understood across a wide range of angiosperm families. Generally, the anther wall comprises the tapetum, the middle layer and the endothecium which are enclosed by the epidermis (Gómez et al. 2015). The innermost tapetum layer is perhaps the most studied due to its crucial role in microspore development (Cigan et al. 2001; Feng and Dickinson 2010; Furness and Rudall 1998, 2001; Parish 2012; Wilson and Zhang 2009). It is adjacent to the developing pollen, providing materials for pollen wall formation and 
coordinating the progression of pollen development. There is growing understanding of the gene networks involved in tapetum differentiation and pollen wall synthesis, and evidence of conservation of these networks across monocot and dicots species (Callens et al. 2018; Drábková and Honys 2017; Gómez et al. 2015; Silva et al. 2016; Theissen and Melzer 2007). This highly regulated process is essential for viable pollen production and male fertility, but despite its importance there are still many unresolved questions regarding the origin, function and communication between the different tissues within the anther. In this review, we explore the conservation and divergence of the anther cell layers to provide an overview of their role in reproductive success. We focus on the complexities of the male reproductive system and evaluate the functions of anther structure and the conservation of the mechanisms behind pollen production and release, and the associated drivers of reproductive success.

\section{Anther development in angiosperms}

Since the first appearance of flowering plants, the angiosperms have become the dominant group of land plants (Bell et al. 2010). The occurrence of the most recent common ancestor (MRCA) of the angiosperms has long been of interest, but has proved difficult to accurately place in an evolutionary timeline. Rapid angiosperm expansion occurred during the Cretaceous period about 65-145 million years ago (Ma) (Doyle 2012; Coiro et al. 2019), possibly with multiple radiation events occurring during this period (Bell et al. 2010). Variability in predictions of the molecular clock and lack of fossil evidence of transitory species add to the difficulty of determining the timing of the MRCA (Barba-Montoya et al. 2018; Bell et al. 2010; Coiro et al. 2019; Murat et al. 2017). The discrepancy between fossil evidence and current molecular models is further complicated by differences in molecular evolution between angiosperms and gymnosperms (De La Torre et al. 2017). Overall angiosperms have a molecular evolution rate that is seven times higher compared to gymnosperms making phylogenetic comparisons more complex (De La Torre, et al 2017). The speed and diversification during the early radiation events of the angiosperms further complicate the dating of the MRCA (Li et al. 2019).

A reconstruction of the anatomy of the ancestral flower suggests the MRCA had ten stamens with introrse (inwardfacing) anthers, arranged in a whorl and separated from other floral organs (Sauquet et al. 2017). This model, based on floral traits across species, has sparked debate regarding the configuration of the angiosperm MRCA flower (DePaula et al. 2018; Rümpler and Theißen 2019; Sokoloff et al. 2018). Despite the controversy regarding the exact anatomy of the first flower structure, anther ontogeny has remained largely unchanged within the angiosperm family (Endress and Doyle 2009).
To address trends in evolution of the angiosperm flower and to put developmental events in perspective, comparisons are often made to living basal angiosperms. The earliest diverging angiosperm is Amborella trichopoda, the only member of the Amborellales order, that various reports have concluded is the sister group of all living angiosperms (Fig. 1) (Amborella Genome Project 2013; Burleigh et al. 2011; Jansen et al. 2007). Phylogenetic studies where eudicots and monocots are compared to the Amborella genome suggest that most of the evolutionary changes in gene networks are shared between closely related taxa (e.g. Solanaceae family), or in terminal branches of the tree (Amborella Genome Project 2013).

Despite complications in determining the MRCA, there is agreement over the initial molecular steps in male reproduction due to the high level of conservation of fundamental stamen development genes within the angiosperm clade (Callens, et al. 2018; Doyle 2012, Theissen and Melzer 2007). Floral development within the angiosperm clade varies extensively, with differences in organisation, number and type of floral organs. Flowers in Arabidopsis develop as four whorls of the floral meristem with the outermost, whorl 1, forming sepals, whorl 2 forming petals, whorl 3 stamens and the innermost whorl 4 forming the carpel (Coen and Meyerowitz 1991). The development and distinctions of these whorls are regulated by classes of genes summarised in the ABCDE model of organ formation. In this model, each class encompasses MADS-box transcription factors that are required for a specific organ differentiation, where the $\mathrm{B}$ and $\mathrm{C}$ genes together with the E genes, generate stamens (Rijpkema et al. 2010; Theißen and Saedler 2001).

Despite differences in flower development, the MADSbox transcription factors described in the ABCDE model are highly conserved among flowering plants (Callens et al. 2018 and references therein). Molecular models suggest the $\mathrm{BC}$ genes responsible for reproductive organ formation predate angiosperms and gymnosperm separation and probably existed $300 \mathrm{Ma}$ (Theissen and Melzer 2007). Despite this timescale, orthologues of the B class genes isolated from the gymnosperm Gnetum gnemon can partially rescue B class mutants in Arabidopsis, supporting a high degree of functional conservation of the MADS-box genes across the plant kingdom (Winter et al. 2002).

\section{Diversity of stamen function and organisation}

The fundamental role of the stamen is to produce and release viable pollen; however, stamen diversification has led to additional functions within the angiosperm clade. Stamen reduction, or repurposing, has occurred many times within angiosperm evolution and has been used to prevent self-pollination, trigger pollinator-stamen contact, protect the ovary from damage and attract pollinators, via intense coloration 


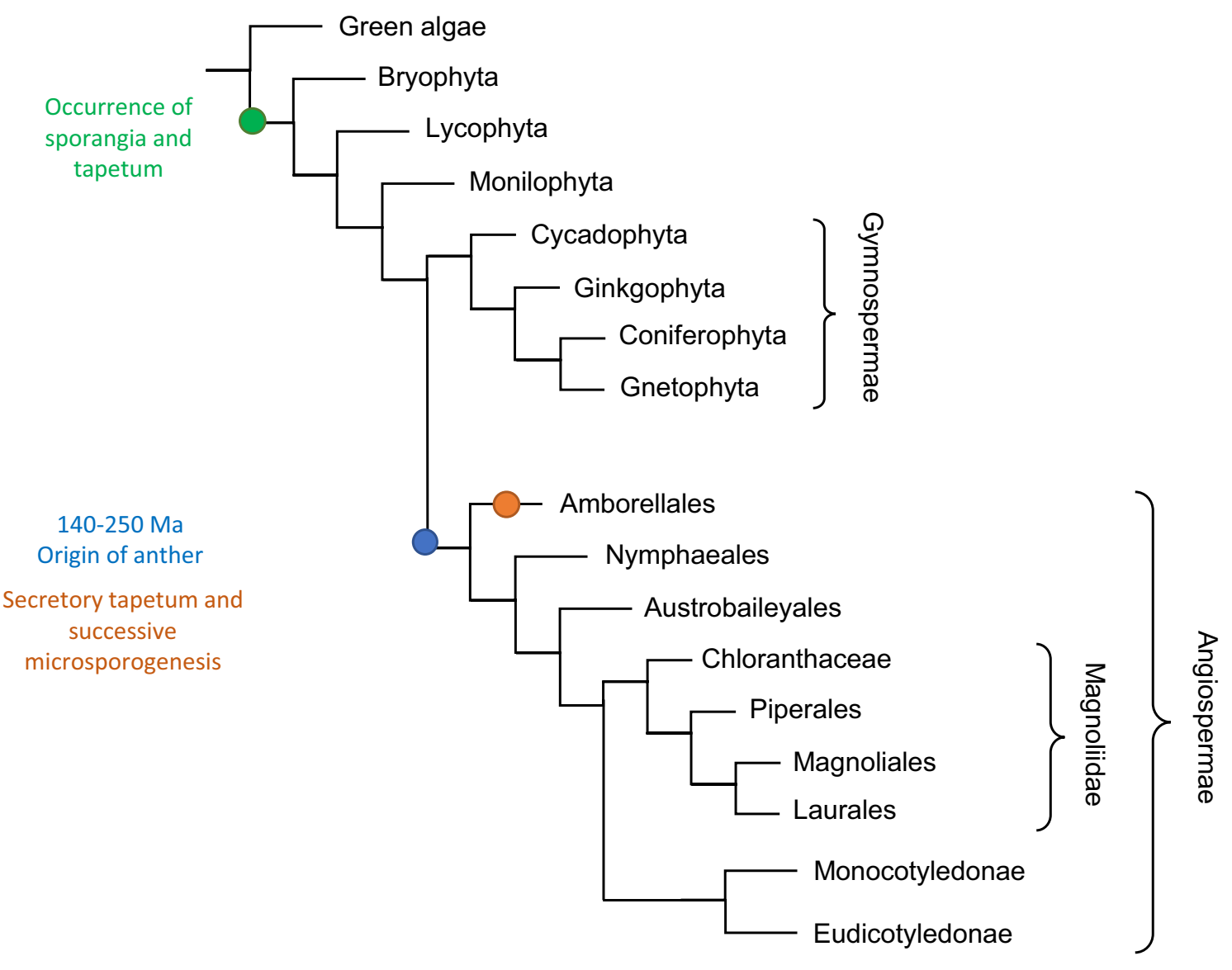

Fig. 1 Phylogenetic tree of land plant evolution. The first angiosperm anther is believed to have occurred 140-250 Ma with the advent of the angiosperm flower (Sauquet et al. 2017). Adapted from (Bhattacharya and Medlin 1998; Endress and Doyle 2009)

and the production of nectar (Walker-Larsen and Harder 2000 and references therein). The diversification of stamens within the same flower, heteranthery, is thought to serve to attract pollinators and enable specific pollinator targeting by sacrificing so-called feeding anthers without impacting overall pollen production (Vallejo-MarÍn et al. 2009). However, recently this view has been challenged by the fact that feeder anthers appear to produce viable pollen and can serve to enhance pollination success by prolonging the timing of pollen release (Kay et al. 2020). This questions this "division of labour" hypothesis and highlights the adaptability and redundancy of the anthers to maximise pollination success (Kay et al. 2020).

In addition to the diversity of stamen function in the angiosperm flower, there is also significant variation in the organisation of stamens. The number of stamens per flower and the type of stamen attachments differ greatly, and these traits are often used as a taxonomic tool for identification of plant families. Stamen filaments also vary, in some basal taxa (e.g. Amborella and some Austrobaileyales) these are flattened sporophyll-like organs with abaxial-adaxial polarity, and this contrasts with the radially symmetrical filaments that are typical of more recently emerged angiosperm lineages (Buzgo et al. 2004; Endress 2001a, b; Endress 1996). Nevertheless, the development and the overall structure of the anther has remained remarkably conserved across the angiosperm clade (Doyle 2012; Endress 2001a, b; Hufford and Endress 1989), with divergence in structure and function focusing towards traits that enhance reproductive success (Endress 1996).

\section{Formation of anther structures from the floral meristem}

The development of the stamen is initiated with the differentiation of the floral primordia in the third whorl. The stamen primordia differentiate early into the filament and the anther, with loss of any of the $\mathrm{B}$ and $\mathrm{C}$ homeotic genes preventing stamen formation (Coen and Meyerowitz 1991). The meristematic cells divide and differentiate to form the reproductive microsporocytes [pollen mother cells (PMCs)] that give rise to the male gametophyte (pollen) and the somatic cell layers that form the surrounding maternal anther walls (Fig. 2). 


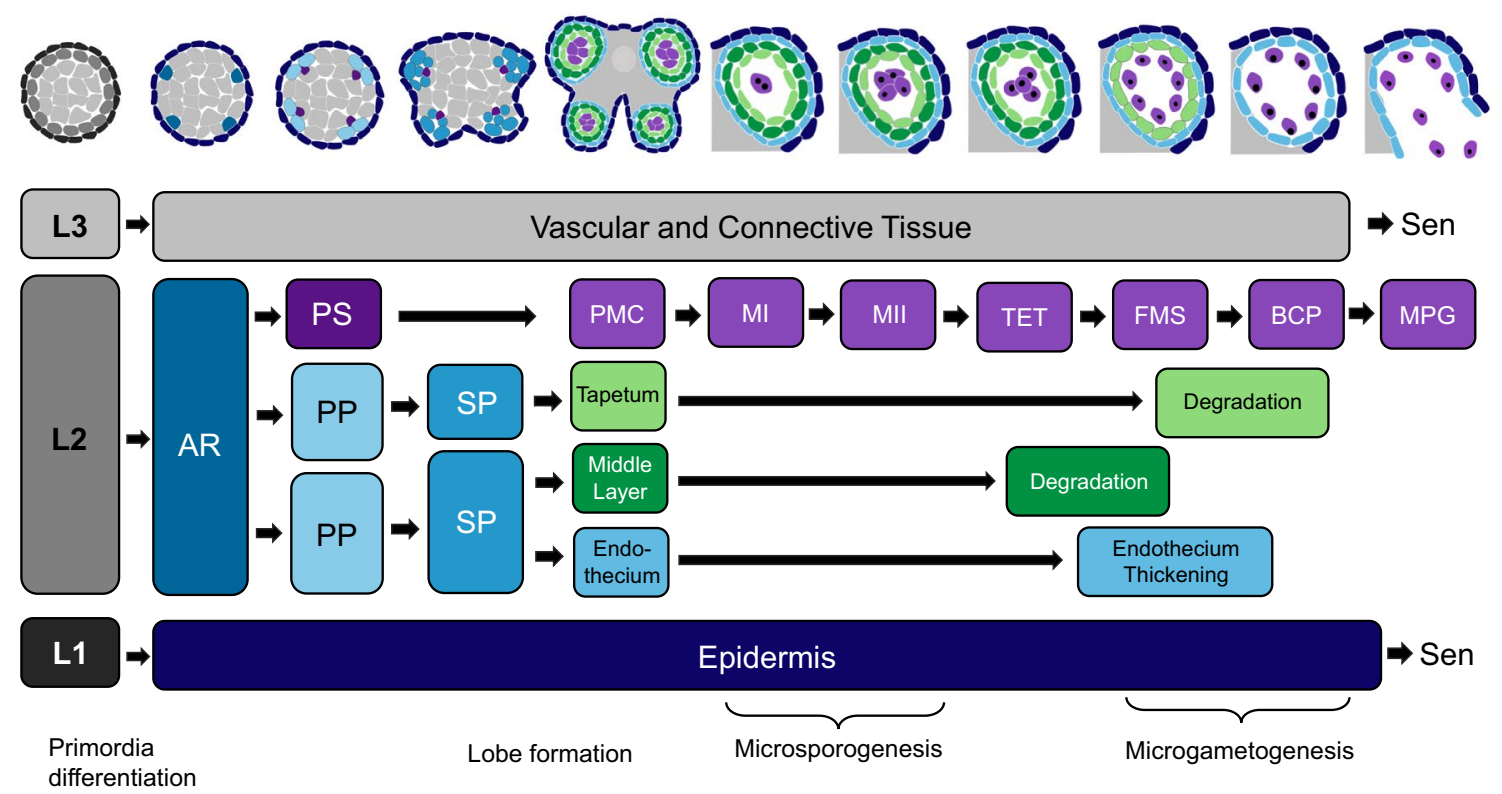

Fig. 2 Schematic view of development of anther layers and microsporogenesis in Arabidopsis. Stamen primordia differentiate into three cell types, L1, L2 and L3, which further differentiate into the epidermis, the archesporial cells and vascular and connective tissues, respectively. Development of the tapetum, middle layer and endothe-

The meristematic cells consist of three germ layers designated L1, L2 and L3 which differentiate to form the anther (Gómez et al. 2015). L1 gives rise to the outermost epidermis and the stomium cell cluster; L2 gives rise to archesporial cells; and L3 gives rise to the connective tissue, vascular bundle and the circular cell cluster (Schnittger et al. 1996). Specification of the anther is initiated by periclinal division of the L2 layer to form archesporial (AR) cells. The AR cells divide to form two cell layers: the reproductive primary sporogenous (PS) cells that later become the microspores and the somatic primary parietal (PP) cells that differentiate into secondary parietal (SP) cells (Canales et al. 2002). These SP cells divide to form the nonreproductive anther wall layers: endothecium, middle layer and tapetum (Scott et al. 2004; Zhang and Yang, 2014). All anther wall layers except the epidermis are derived from L2 cells (Kelliher and Walbot 2011). Timely formation and degeneration of the various anther layers are essential for viable pollen production. Each layer provides vital functions for microspore development or subsequent pollen release, with failure to form or degenerate at the correct developmental stage leading to male sterility. This is particularly evident for defects associated with the tapetum, which is seen in both cytoplasmic male sterile and genic male sterile mutants used in hybrid plant breeding (Kaul 1988).

\section{Differential formation of anther layers}

The anther wall layers develop through division of the SP layers in one of four types: basic, dicotyledonous, cium follow the dicot model. AR: archesporial cells, BCP: bicellular pollen, FMS: free microspore, MI: meiosis I, MII: meiosis II, MPG: mature pollen grain, PMC: pollen mother cell, PP: primary parietal, PS: primary sporogenous, Sen: senescence, SP: secondary parietal, TET: tetrad

monocotyledonous and reduced (Fig. 3) (Kelliher et al. 2014). It appears that all types follow the same pattern of stamen primordia differentiation until the development of the SP layers, after which the division of these two cell layers determines the formation type. According to Davis (1966) in the most primitive type (basic type), the two SP cell layers divide once each to form four layers: one endothecium, two middle layers and one tapetum. The dicot and the monocot types both result in three layers: one endothecium, one middle layer and one tapetum. The difference is in the origin of these layers, in the dicot model only the outer SP layer divides to form the endothecium and the middle layer, whereas in the monocot model only the inner SP layer divides to form the middle layer and tapetum. In the reduced form, no division occurs, but the two SP layers differentiate to form the endothecium and the tapetum without the middle layer (Davis 1966).

After the differentiation of the cell layers, additional divisions can occur in the endothecium or middle layer to produce extra layers (Carrizo García 2002b). The number of additional layers produced depends on the species and can vary greatly within plant families (Carrizo García 2002b). In members of the Solanaceae family, species forming via the basic type appear to have more variation in the number of middle layers formed, whereas species developing via the dicot formation type rarely formed more than one additional layer (Carrizo García 2002a). In the vast majority of plant species, only one type of anther wall formation is deployed and the same number of wall layers are produced, but there 


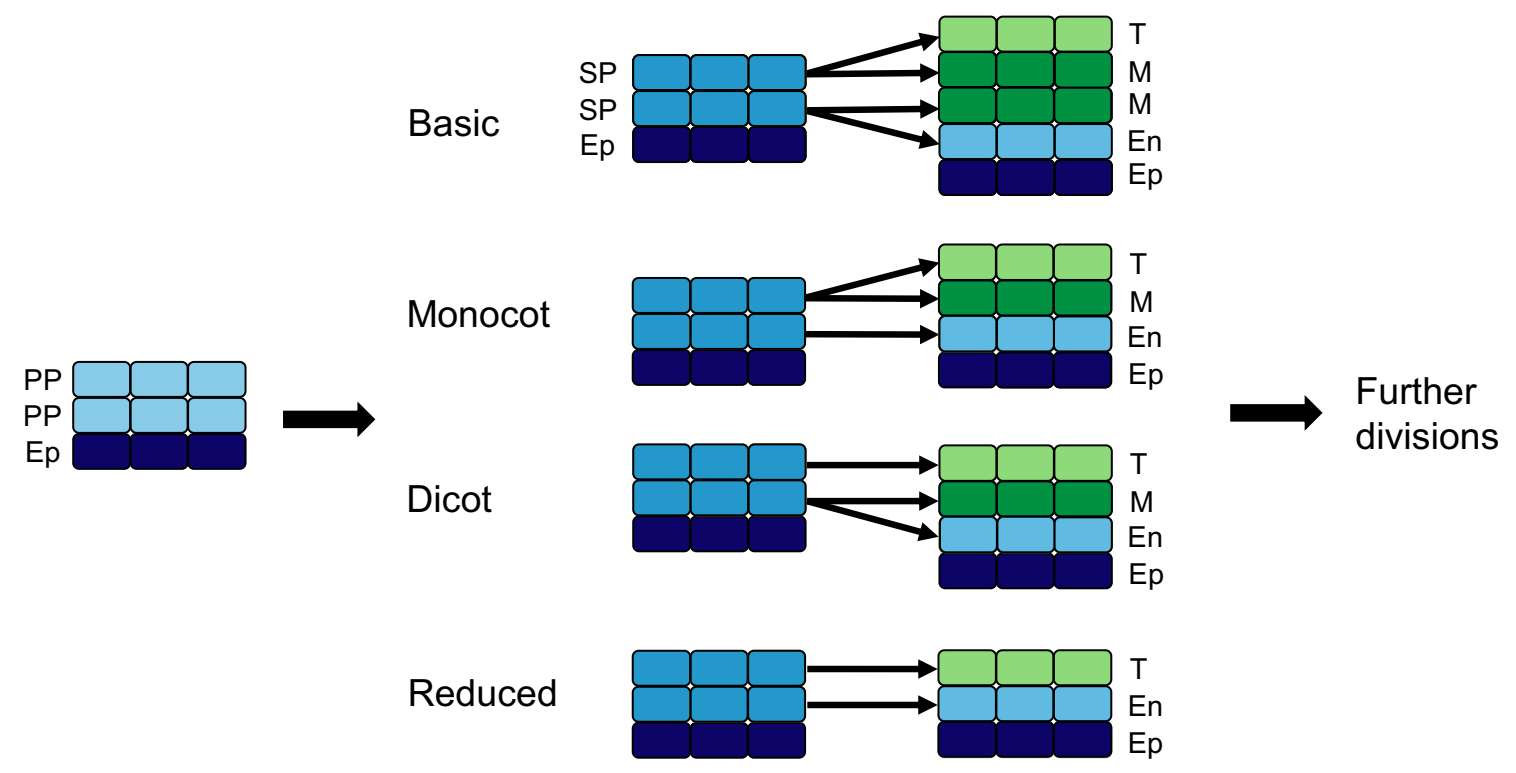

Fig. 3 Anther wall formation types (adapted from Davis 1966). In all formation types, the epidermis (dark blue) surrounds the primary parietal cells that differentiate to form secondary parietal cells. The SP cells then differentiate into the endothecium (light blue), middle

are also examples of two formation types being used within the same anther (Bhandari and Sharma 1987; Hermann and Palser 2000); however, the significance of these differences for pollen development remains unclear.

It has been suggested that the number of cells in the individual anther layers is important to microspore development. Kelliher and Walbot (2011) hypothesise that the middle layer and tapetum form clusters of cells dedicated to the development of specific pollen grains in maize. Derivates of a single SP cell are then earmarked for individual microspores; mutants where the cell layers are abnormal often fail to produce viable pollen (Feng and Dickinson 2010). There is also evidence that the somatic cell layers provide developmental cues to the forming microsporocytes (Wilson and Zhang 2009), including hormone signals regulating anther development (Cecchetti et al. 2017). These observations further support the importance of the correct division, timing and differentiation of SP cells for viable pollen development.

\section{Anther wall development and function}

To a certain extent, the anther cell wall division type is conserved within a phylogenetic group; however, some families display multiple division types suggesting they have evolved several times in angiosperms (Carrizo García 2002b). Anthers in the earliest divergent angiosperm Amborella, develop via the "basic type" system (Tobe et al. 2000), whilst the "dicot type" appears to have evolved early in the angiosperm clade in Schisandraceae, in the Austrobaileyales layer (dark green) and tapetum (light green), according to the formation type associated with each species. Ep: epidermis, En: endothecium, M: middle layer, PP: primary sporogenous cells, SP: secondary sporogenous cells, T: tapetum

order (Vljayaraghavan and Dhar 1975). In monocots, most members of the Poales order have the monocot type of anther wall development, but some early divergent members have the reduced or the basic type (Sajo et al. 2009). In the Asteraceae, the largest family of the dicots, anthers tend to develop through the dicot type (Ao et al. 2009), whereas in the Solanaceae species, $64 \%$ have a basic-type anther and $36 \%$ dicot (Carrizo García 2002b). In other families, such as the Ericaceae, several anther types exist (Hermann and Palser 2000), suggesting that the formation type is labile and highly variable throughout the angiosperm clade.

Since the introduction of this system of anther wall classification by Davis (1966), the pattern of cell division of the lineages is generally represented as occurring sequentially in all cells. This view is further supported by studies of anther development where a transverse anther section shows synchronised cells in one plane as representative for the entire anther. There is, however, very little information on the timing of the specification throughout the length of the anther, and the division pattern might not be as rigid as previously thought. When the anther is imaged longitudinally, there seems to be more flexibility in the origin of the cell layers rather than the strict somatic or germinal cell fates depicted in the traditional models (Kelliher, et al. 2014). The cells do not differentiate immediately after divisions, but go through mitosis at different rates making it difficult to determine a single anther wall formation type (Kelliher et al. 2014). Additionally, the classifications offered by Davis (1966) might not encompass all forms of anther wall development. 
For example, in many species in the Ericaceae the anther wall layers divide in a pattern that cannot be applied to any of the current types (Hermann and Palser 2000), suggesting that the manner of division of the SP cell layers is complex and diverse.

\section{Evolution of sporogenous cells}

Alongside the formation of the anther wall layers from secondary sporogenous cells, the reproductive primary sporogenous cells divide to form the pollen mother cells (PMCs), which go through meiosis to form microspores and subsequently develop into pollen grains. It is in the microsporangia that the microspores divide and develop into mature pollen grains, through the support of the surrounding anther wall layers and the deposition of the intricate pollen wall (Furness et al. 2002). In general, an anther contains four microsporangia divided into two thecae (Endress 1996). The development of sporangia was one of the key innovations which enabled plants to colonise the land, since within these structures hardy spores could be formed which enabled dispersal of genetic material in dry environments (Tanurdzic and Banks 2004).

As a crucial part of the lifecycle of all plants, sporangia exist even in the most basal of land plants: the non-vascular bryophytes (liverworts, hornworts and mosses) and vascular lycophytes (club mosses, spike mosses and whisk ferns) and monilophytes (true ferns). Sporangia have evolved to efficiently disperse spores. In the case of ferns the developing spore mother cells undergo meiosis surrounded by a layer of annulus cells, which dehydrate to cause the sporangia to open at the stomium in a catapult-like manner to rapidly discharge the spores (Noblin et al. 2012). In turn, these spores develop into the gametophytes, which contain antheridia where the sperm cells are produced.

In seed-setting plants, the gametophyte stage is simply condensed into the developing microspore and the mature pollen is essentially the antheridium. Stamens evolved from leaf-like structures bearing microsporangia. Most extant spermatophytes possess stamen-like structures, containing microsporocytes which undergo meiosis to form haploid microspores and subsequently develop into mature pollen grains. The development of pollen from microsporangia is a conserved process for all heterosporous plants including angiosperms and gymnosperms. In terms of thecal organisation, the "stamens" of gymnosperms such as Gingko biloba, Gnetum and conifers are more simplistic than their angiosperm counterparts. Whereas angiosperm stamens typically have four microsporangia arranged into two theca on each side of the stamen, gymnosperm stamens are disporangiate with a singular microsporangium situated on each side of the filament and thus have no theca (Endress 2001a, b). Whilst there are some angiosperm groups that lack theca (Endress and Stumpf 1990) arguably, organisation of microsporangia into theca was a key innovation in angiosperm anther evolution that has enabled more efficient pollen release.

\section{Microsporogenesis types}

During microsporogenesis, the microsporocytes go through two rounds of meiosis inside the microsporangia to form microspores. Generally, there are two types of microsporogenesis observed, simultaneous and successive, although intermediate types are increasingly being discovered. The types differ in the timing of meiosis in relation to the separation of microspores by the formation of the callose wall. In simultaneous microsporogenesis, meiosis I and II occur without interruption simultaneously alongside callose wall deposition, generally resulting in tetrahedral tetrads. In the successive type there is a pause between meiosis I and II where the callose wall is deposited to form distinct dyads, typically producing tetragonal tetrads (Sajo et al. 2009). However, Furness et al. (2002) argue that the types of microsporogenesis are more complicated than just the simultaneous and the successive, and that the intermediate type is more common than previously thought. Fossil records from the Ordovician period (444-489 Ma) have identified the simultaneous type, prior to the appearance of angiosperms (Furness et al. 2002). In the earliest divergent species from the angiosperms, the Amborellales (Tobe et al. 2000) and members of the Nymphaeales (Taylor and Osborn 2006), the microsporogenesis is successive, suggesting the first angiosperm anther developed via the successive type of microsporogenesis. Most eudicots have simultaneous microsporogenesis with few exceptions (Furness et al. 2002), whereas in the monocots the successive type is predominant, but there are several families where the simultaneous is seen. Taken together, this suggests there have been multiple events of either secondary loss or divergent evolution of the simultaneous and successive types, and a high degree of specificity is preferred in the microsporogenesis type (Furness et al. 2002). However, the significance of this in relation to pollen function and resilience is currently unclear.

\section{Evolution of tapetum formation and function}

The tapetum is the innermost layer of the anther walls (Fig. 2), which is critical for the regulation of pollen development and the synthesis of the pollen wall. Tapetal cells go through a regulated Programmed Cell Death (PCD) that is required for viable pollen formation, where wall materials, such as carbohydrates, lipidic molecules, sporopollenin precursors and nutrients, are secreted into the locules and the developing microspores (Zhang et al. 2011). This specialised cell layer is essential for microspore nutrition and is present in all land plants from the more basal bryophytes to 
spermatophytes under various descriptors, such as "nutritive cells" or "spore sac layer cells" (Pacini et al. 1985).

The tapetum is almost exclusively single layered; multilayered tapeta are very rare in angiosperms, and in monocotyledons, it has been reported only in Abolboda and Orectanthe in the Xyridaceae family (Oriani and Scatena 2015). The number of layers of the anther wall seems to be critical for pollen production, with changes in the tapetum being particularly detrimental, with additional tapetum layers resulting in male sterility (Cecchetti et al. 2015; Chaubal et al. 2000, Feng and Dickinson 2010).

There are generally two types of tapeta. The first is the secretory, or glandular, where the tapetum remains in situ in the anther locule whilst synthesising and secreting pollen wall materials, and subsequently breaks down. The other is the plasmodial, or amoeboid type, where the tapetum cell walls break down to release protoplasts that fuse to form a multinucleate plasmodium. A third, less common, type is the invasive tapetum, which is mostly found in the Asteraceae, where the cell walls of the tapetum dissolve and disperse among the developing microspores (Tiwari and Gunning 1986). Individuals usually have only one type of tapetum, but there are occasions, e.g. in safflower Carthamus tinctorius, where two types of tapetal cells coexist (Yeung et al. 2011). Additionally, Sajo et al (2005) hypothesise there might be an intermediate tapetum type, where an early-stage secretory tapetum subsequently becomes invasive. The significance of two types coexisting, working independently or transitioning from one to another is still unclear, but it suggests there are intricate adaptations and specific regulation of tapetum development.

Both secretory and plasmodial types are common in dicots and monocots. The secretory tapetum probably had several independent origins (Oriani and Scatena 2015) and is regarded as the most primitive form (Furness and Rudall 1998; Pacini et al. 1985). The early divergent angiosperm Amborella has a secretory tapetum (Tobe et al. 2000), which also appears to be the most common type in primitive dicotyledons (Furness and Rudall 1998). Both types of tapeta are found throughout the monocot clade, suggesting secretory and plasmodial forms have evolved several times in monocotyledons (Furness and Rudall 1998). The variability in tapetum type within the angiosperm clade, where reversals or re-evolving of the types occurs throughout the taxa, again further supports the significance of the tapetum and the importance of precise control of its development and function.

\section{Variability and function of the anther middle layer in pollen development}

The function of the middle layer is not fully established since mutants displaying middle layer defects also tend to show tapetum abnormalities, making it difficult to determine its independent function. The middle layer was long thought to have no function and be a leftover relic from pre-angiosperm anther structures (Davis 1966). More recently, however, it has been shown to have a secretory function similar to the tapetum, with failure in degeneration leading to male sterility through delayed exine deposition (Falasca et al. 2013). Once the middle layer has formed it becomes thinner throughout pollen formation and is completely degenerated by anther dehiscence. Kelliher and Walbot (2011) hypothesise that the tapetum and middle layer derive from a single secondary parietal cell, providing the nutrients required for the development of a single microspore.

The middle layer is important for pollen formation in many species yet there is high variability in the number of middle layers. No middle layer is formed in reduced-type anthers (Fig. 3), whereas some species undergo additional divisions to form multiple layers, with as many as nine middle layers in Hawkesiophyton panamense in the Solanaceae family (Carrizo García 2002a). The reason for this diversity in the number of layers, along with the specific function of the middle layer is currently not known, although may be due to environmental responses. In cereal crops, drought stress during the meiotic and mitotic stages can lead to an expanded middle layer, possibly due to increase sugar transport to the microspores in response to water deficiency ( $\mathrm{Yu}$ et al. 2019). In late stamen development, the middle layer is involved in pollen maturation and anther dehiscence by controlling auxin signalling (Cecchetti et al. 2017), suggesting that the middle layer may be important in signalling during multiple stages of anther and pollen development.

\section{The importance of anther wall PCD for sex determination}

Developmentally programmed cell death (dPCD) is an integral process for pollen development and release, as well as floral organ differentiation (reviewed in Wang et al. 2021). Degeneration of the tapetum and the middle layer provides nutrients to the developing microspore, and degradation of the septum and stomium facilitates anther opening. A common cause of male sterility is the mistimed degeneration of anther wall layers, primarily the tapetum. Mistimed PCD prevents viable pollen formation and is one of the strategies developed by angiosperms to produce unisexual flowers (Flores-Rentería et al. 2013; Hernández-Cruz et al. 2019; Ren et al. 2019). Normal degeneration of the tapetum and middle layer tissues is vital for the provision of nutrients and wall materials for pollen maturation. Infertility in a variety of species such as Tapiscia sinensis, an androdioecious tree, or in dioecious cacti, in the Opuntia family is ensured by preventing the deposition of essentials materials for mature pollen formation, without the need to restructure the anther 
(Flores-Rentería et al. 2013; Hernández-Cruz et al. 2019; Ren et al. 2019).

\section{Anther dehiscence}

\section{Types of anther dehiscence}

Across the angiosperm clade, many different types of dehiscence have evolved. The way in which the anther opens is one of many factors that determines the pollination syndrome of a flower (Bernhardt 1996). The dehiscence process is determined by the shape, position and anatomical features of the stomium, endothecium as well as the anther attachment point.

There are four known types of anther splitting: longitudinal, transverse, poricidal and valvate that can occur as introrse (pollen release towards the centre of the flower) or extrorse (pollen release outwards, away from the centre of the flower). In longitudinal dehiscence, the anther splits along the long axis of the theca and is the most common method of anther opening. It is typical of many angiosperms and is found in both monocotyledonous and dicotyledonous species in a wide taxonomic range. Transverse dehiscence is similar to longitudinal dehiscence; however, the split is at right angles to the long axis of the theca. Poricidal dehiscence can be seen in anthers that shed their pollen via terminal apertures, for example in members of the Melastomataceae (Renner 1989), Solanaceae (Bohs 2005) and Leguminosae (Marazzi et al. 2007). Poricidal dehiscence has adaptive value to pollinators capable of collecting pollen by the high frequency vibration of stamens (De Luca and Vallejo-Marín 2013; Larson and Barrett 1999). Finally, valvate dehiscence is where pollen is released through a pore that is covered by a flap of tissue. This type of dehiscence is rare, but is occasionally seen in members of the Hamamelidaceae (Hufford and Endress 1989), Magnoliids (Endress and Hufford 1989) and Berberidaceae (Batygina 2002).

\section{Endothecium development and secondary thickening}

Multiple anther wall layers appear to work collectively not only in the development of the microspores, but in the release of mature pollen grains. The endothecium plays an important role in anther dehiscence and pollen release by interacting with the middle layer and the tapetum. After microspore meiosis, alongside degeneration of the tapetum and middle layers, the endothecium undergoes specific secondary thickening (Wilson et al. 2011). Thickening of the endothecial layer occurs prior to anther dehiscence and serves to build tension in the remaining anther layers to generate sufficient force to break the stomium, retract the anther walls as they dehydrate and disperse the pollen (Keijzer 1987; Nelson et al. 2012). In addition to aiding anther dehiscence, the endothecium appears to serve as a last storage site for lipids during the final stages of pollen development, and fatty acids derived from the endothecium are thought to help facilitate pollen hydration (Zhan et al. 2018; Zhu et al. 2020). Formation of secondary wall thickening in the Arabidopsis endothecium layer appears to be regulated principally by three transcription factors MYB26, NAC Secondary Wall Promoting Factor 1 (NST1) and NST2 (Mitsuda et al. 2005; Yang et al. 2007 2017). This secondary thickening process appears conserved across different species and is at least in part orchestrated via auxin signalling (Cecchetti et al. 2013); however, few genes have been isolated that are specific to the endothecium.

Endothecial secondary thickening is highly variable between taxa with distinct deposition patterns impacting anther opening. Attempts have been made to draw phylogenetic information from these patterns, but this has been unsuccessful due to the complex interspecies variation observed (Carrizo García 2002a). Endothecial thickening patterns seem insensitive to ecological influences and there is no direct correlation between them and the dehiscence type (Manning 1996). For example, Manning (1996) highlights that "U-shaped" thickenings occur in different species with each of the different dehiscence types, in anthers that are versatile (filament attached at the centre) or basifixed (filament attached at the base).

Some angiosperm clades do not develop endothecium thickening, but utilise alternative mechanisms to generate the force required to open the stomium. These include some species within the Ericaceae (Hermann and Palser 2000), Leguminosae (Marazzi et al. 2007) and Melastomataceae (Cortez et al. 2014). Most species within the Ericaceae form an alternative specific fibrous tissue called the resorption tissue that has been reported to be involved in anther dehiscence (Hermann and Palser 2000). The Senna group of the Leguminosae rely on thick walled hypodermal and subhypodermal cells as an alternative to the classical thickening of the endothecium (Marazzi et al. 2007). Uniquely, the Melastomataceae represents one of few families with poricidal dehiscence that does not have a specialised mechanical tissue (Cortez et al. 2014). Successful dehiscence in this family relies on specific dehydration of cells in the pore region of the anther, whilst the cuticle prevents dehydration of the surrounding cells (Cortez et al. 2014).

\section{Anther stomium and septum degeneration}

For pollen to be released from the anther, the septum and stomium must undergo controlled degeneration. During anther dehiscence the septum, a region of cells located between the lobes of the theca, degrades to create a single 
lobe. The stomium is formed by differentiation of epidermal cells along the anther which produces a single cell region through which pollen will be released (Wilson et al. 2011). This differentiation of cells in the epidermis occurs early in development, at a similar time to when the tapetum forms (Bonner and Dickinson 1989).

Solanaceous species have a unique adaptation that is not found in either Arabidopsis or Lilium. They possess specialised cells in the "notch" region under the stomium called the circular cell cluster (also referred to as: intersporangial septum, hypodermal septum or oxalate package). These highly specialised subepidermal cells, derived from the L2 primordium that accumulate and release calcium oxalate, which is thought to be important for dehiscence and to provide calcium for pollen germination (Iwano et al. 2004). Cells within the circular cell cluster degenerate prior to those in the stomium, facilitating the formation of a bilocular anther. In other non-solanaceous species that lack a circular cell cluster, this role is facilitated by different non-specific cells found in the "notch" region.

\section{Anther dehydration}

Anther dehydration is one of the final processes that facilitate anther dehiscence and pollen release. Firstly, once the pollen grains have fully developed, the locular fluid is removed to facilitate pollen dispersal. Next, the anther wall is dehydrated, which is hypothesised to be crucial to generate the required force to bend and open the anther (Nelson et al. 2012). This process is orchestrated by dehydration of the anther walls causing the anthers to retract (Keijzer 1987). In cereal crops, temperature has been shown to influence anther dehiscence (Fernández-Gómez et al. 2020; Matsui and Hasegawa 2019). In barley, the fertility of $H v M S 1$ overexpression lines display temperature dependent reversible sterility. Anthers of the HvMSl overexpression line produce viable pollen, but fail to dehisce at lower temperature and lead to a reduction in seed set in barley (Fernández-Gómez et al. 2020). Additionally, the duration of anther dehiscence influences seed set in rice, specifically at higher temperatures longer anther dehiscence is seen which favourably improves pollination (Matsui and Hasegawa 2019).

\section{Impact of hormones on stamen development and pollen release}

Most hormones have been shown to be involved in all stages of stamen development, as reviewed by Chandler (2011). Gibberellins have generally been associated with early filament elongation and tapetum development, whereas jasmonic acid (JA) has been linked to later stages of pollen maturation, filament extension and anther dehiscence in higher land plants (Marciniak and Przedniczek 2019; Susheng Song et al. 2011). The effects of hormonal signalling on fertility are not always conserved among land plants. In Arabidopsis, MYC proteins promote stamen development by activating JA signalling (Chen et al. 2016), whereas the orthologous MYC proteins in the liverwort Marchantia polymorpha do not affect fertility despite being involved with JA signalling (Peñuelas et al. 2019).

Defects in auxin signalling through the disruption of ARF6 and ARF8 function prevents stomium degeneration and pollen release (Nagpal et al. 2005; Zheng et al. 2019). In addition, the function and production of auxin in regard to floral organ initiation have been shown to be conserved in highly diverged plant families, suggesting the hormonal network evolved in an common ancestor (Chandler 2011 and references therein).

Lack of information in basal lineages has made it difficult to confirm the evolution of the auxin pathway in vascular plants. The auxin response is proposed to have emerged as a response to multicellular growth in land plants, although this can be questioned by the presence of auxin pathways in green, red and brown algae (De Smet et al. 2011; Lau et al. 2009; Le Bail et al. 2010; Rensing et al. 2007; Sztein et al. 2000). Identification of a putative functional YUCCA gene, involved in auxin biosynthesis, in green algae suggests some conservation in basal lineages of land plants (De Smet et al. 2011). Furthermore, bryophytes have been shown to have a basic nuclear auxin pathway that contains three classes of ARFs and TIR1/AFB-AUX/IAA co-receptor, indicating the presence of an auxin response pathway in a common ancestor of land plants (Kato et al. 2018; Lavy et al. 2016; Plavskin et al. 2016; Tsuzuki et al. 2016). It is thought that ARF-like transcription factors and auxin co-receptors were established in charophytes, but their involvement in auxin signalling is unknown (Kato et al. 2018; Wang et al. 2015). The role of auxin in the regulation of anther dehiscence has been established in land plants such as Arabidopsis (Cecchetti et al. 2013) and rice (Shiyong Song et al. 2018; Zhao et al. 2013). However, better understanding of the evolutionary development of this response in land plants, compared to basal lineages, requires the identification of hormonal response in more diverse species.

\section{Conclusions}

The evolution of the anther was a key event associated with the reproductive success of the angiosperms. The complexity and diversity in the formation, anatomy and dehiscence of the male reproductive organ highlight the importance of the stringent control required for successful pollination. Model species allow detailed study of these phenomena; however, significant diversity exists throughout the angiosperm clade which is important to acknowledge to prevent 
generalisations about pollination. Studying pollen development and the anther function in an evolutionary context helps facilitate understanding of essential genetic pathways and developmental events, and can be used to further sustainable plant breeding and agricultural practices.

Authors' contribution All authors contributed to the article conception. JA wrote the manuscript with support from CK and BT. JA and CK designed the artwork. JA, JR, CK and ZW edited the manuscript.

Funding ZAW receives funding from the Biotechnology and Biological Sciences Research Council (BBSRC) [grant no. BB/P002080/1]; JA is supported by a University of Nottingham (UoN) BBSRC Doctoral Training Partnership (DTP) NPIF CASE award with support from Agriculture and Horticulture Development Board (AHDB), KWS UK Ltd, Limagrain UK Ltd, RAGT Seeds Ltd, and SECOBRA Recherches. CK is supported by a UoN BBSRC DTP CASE with KWS UK Ltd, and Syngenta Seeds. JKR is supported through UoN BBSRC DTP; BT is supported by the Royal Society Challenge-led (Grant No. CHLI R1\180496)

\section{Declarations}

Conflict of interests The authors have no conflicts of interest to declare that are relevant to the content of this article.

Open Access This article is licensed under a Creative Commons Attribution 4.0 International License, which permits use, sharing, adaptation, distribution and reproduction in any medium or format, as long as you give appropriate credit to the original author(s) and the source, provide a link to the Creative Commons licence, and indicate if changes were made. The images or other third party material in this article are included in the article's Creative Commons licence, unless indicated otherwise in a credit line to the material. If material is not included in the article's Creative Commons licence and your intended use is not permitted by statutory regulation or exceeds the permitted use, you will need to obtain permission directly from the copyright holder. To view a copy of this licence, visit http://creativecommons.org/licenses/by/4.0/.

\section{References}

Amborella Genome Project (2013) The Amborella genome and the evolution of flowering plants. Science. https://doi.org/10.1126/ science. 1241089

Ao C, Wang L, Liang L, Wang X (2009) Anther wall formation, microsporogenesis and male gametogenesis of four closely related species in Astereae (Asteraceae): description, comparison and systematic implications. Nord J Bot 27(4):292-297. https://doi. org/10.1111/j.1756-1051.2009.00331.x

Barba-Montoya J, dos Reis M, Schneider H, Donoghue PCJ, Yang Z (2018) Constraining uncertainty in the timescale of angiosperm evolution and the veracity of a Cretaceous Terrestrial Revolution. New Phytol 218(2):819-834. https://doi.org/10.1111/nph.15011

Batygina TB (2002) Embryology of flowering plants: Terminology and concepts. Generative organs of flowers, 1st edn. Science Pub Inc., Enfield

Bell CD, Soltis DE, Soltis PS (2010) The age and diversification of the angiosperms re-revisited. Am J Bot 97(8):1296-1303. https://doi. org/10.3732/ajb.0900346
Bernhardt P (1996) Anther adaptation in animal pollination. In: D’Arcy WG, Keating RC (eds) The anther form, function and phylogeny. Cambridge University Press, Cambridge, pp 192-220

Bhandari N, Sharma M (1987) Histochemical and ultrastructural studies during anther development in Solanum nigrum L I. Early ontogeny. Phytomorphology 37:249-260

Bhattacharya D, Medlin L (1998) Algal phylogeny and the origin of land plants. Plant Physiol 116(1):9-15. https://doi.org/10.1104/ pp.116.1.9

Bohs L (2005) Major clades in solanum based on ndhF sequence data. In: Keating R, Hollowell VC, Croat T (eds) A festschrift for William G. D'Arcy: The legacy of a taxonomist. Missouri Botanical Garden Press, St. Louis, pp 27-49

Bonner LJ, Dickinson HG (1989) Anther dehiscence in Lycopersicon esculentum Mill. New Phytol 113:97-115. https://doi.org/10. 1111/j.1469-8137.1989.tb02399.x

Burleigh JG, Bansal MS, Eulenstein O, Hartmann S, Wehe A, Vision TJ (2011) Genome-scale phylogenetics: Inferring the plant tree of life from 18,896 gene trees. Syst Biol 60(2):117-125. https:// doi.org/10.1093/sysbio/syq072

Buzgo M, Soltis PS, Soltis DE (2004) Floral Developmental Morphology of Amborella trichopoda (Amborellaceae). Int J Plant Sci 165(6):925-947

Callens C, Tucker MR, Zhang D, Wilson ZA (2018) Dissecting the role of MADS-box genes in monocot floral development and diversity. J Exp Bot 69(10):2435-2459. https://doi.org/10.1093/ jxb/ery086

Canales C, Bhatt AM, Scott R, Dickinson H (2002) EXS, a putative LRR receptor kinase, regulates male germline cell number and tapetal identity and promotes seed development in Arabidopsis. Curr Biol 12(20):1718-1727. https://doi.org/10.1016/S09609822(02)01151-X

Carrizo García C (2002a) An approach to the diversity of endothecial thickenings in Solanaceae. Flora 197(3):214-223. https://doi.org/ 10.1078/0367-2530-00032

Carrizo García C (2002b) Anther wall formation in Solanaceae species. Ann Bot 90(6):701-706. https://doi.org/10.1093/aob/mcf248

Cecchetti V, Altamura MM, Brunetti P, Petrocelli V, Falasca G, Ljung K, Costantino P, Cardarelli M (2013) Auxin controls Arabidopsis anther dehiscence by regulating endothecium lignification and jasmonic acid biosynthesis. Plant J 74(3):411-422. https://doi. org/10.1111/tpj.12130

Cecchetti V, Brunetti P, Napoli N, Fattorini L, Altamura MM, Costantino P, Cardarelli M (2015) ABCB1 and ABCB19 auxin transporters have synergistic effects on early and late Arabidopsis anther development. J Integr Plant Biol 57(12):1089-1098. https://doi.org/10.1111/jipb.12332

Cecchetti V, Celebrin D, Napoli N, Ghelli R, Brunetti P, Costantino P, Cardarelli M (2017) An auxin maximum in the middle layer controls stamen development and pollen maturation in Arabidopsis. New Phytol 213(3):1194-1207. https://doi.org/10.1111/ nph. 14207

Chandler JW (2011) The hormonal regulation of flower development. J Plant Growth Regul 30(2):242-254. https://doi.org/10.1007/ s00344-010-9180-X

Chaubal R, Zanella C, Trimnell MR, Fox TW, Albertsen MC, Bedinger P (2000) Two male-sterile mutants of Zea mays (Poaceae) with an extra cell division in the anther wall. Am J Bot 87(8):11931201. https://doi.org/10.2307/2656657

Chen X, Huang H, Qi T, Liu B, Song S (2016) New perspective of the bHLH-MYB complex in jasmonate-regulated plant fertility in arabidopsis. Plant Signal Behav 11(2):1-4. https://doi.org/10. 1080/15592324.2015.1135280

Cigan AM, Unger E, Xu R, Kendall T, Fox TW (2001) Phenotypic complementation of ms 45 requires tapetal expression of MS45. 
Sex Plant Reprod 14:135-142. https://doi.org/10.1007/s0049 70100099

Coen ES, Meyerowitz EM (1991) The war of the whorls: genetic interactions controlling flower development. Nature 353(6339):31. https://doi.org/10.1038/353031a0

Coiro M, Doyle JA, Hilton J (2019) How deep is the conflict between molecular and fossil evidence on the age of angiosperms? New Phytol 223(1):83-99. https://doi.org/10.1111/nph.15708

Cortez PA, Caetano AP et al (2014) Elucidating the mechanism of poricidal anther dehiscence in Miconia species (Melastomataceae). Flora 209(10):571-579. https://doi.org/10.1016/j.flora. 2014.07.002

Davis GL (1966) Systematic embryology of the angiosperms. Wiley, New York

De-Paula OC, Assis LCS, Ronse de Craene LP (2018) Unbuttoning the ancestral flower of angiosperms. Trends Plant Sci 23(7):551-554. https://doi.org/10.1016/j.tplants.2018.05.006

De La Torre AR, Li Z, Van De Peer Y, Ingvarsson PK (2017) Contrasting rates of molecular evolution and patterns of selection among gymnosperms and flowering plants. Mol Biol Evol 34(6):1363-1377. https://doi.org/10.1093/molbev/msx069

De Luca PA, Vallejo-Marín M (2013) What's the "buzz" about? The ecology and evolutionary significance of buzz-pollination. Curr Opin Plant Biol 16(4):429-435. https://doi.org/10.1016/j. pbi.2013.05.002

De Smet I, Voß U, Lau S, Wilson M, Shao N, Timme RE, Swarup R, Kerr I, Hodgman C, Bock R, Bennett M, Jürgens G, Beeckman $\mathrm{T}$ (2011) Unraveling the evolution of auxin signaling. Plant Physiol 155(1):209-221. https://doi.org/10.1104/pp.110. 168161

Doyle JA (2012) Molecular and fossil evidence on the origin of angiosperms. Annu Rev Earth Planet Sci 40(May):301-326. https:// doi.org/10.1146/annurev-earth-042711-105313

Drábková LZ, Honys D (2017) Evolutionary history of callose synthases in terrestrial plants with emphasis on proteins involved in male gametophyte development. PLoS ONE 12(11):1-24. https:// doi.org/10.1371/journal.pone.0187331

Endress PK, Stumpf S (1990) Non-tetrasporangiate stamens in the angiosperms: structure, systemic distribution and evolutionary aspects. Schweizerbart'sche Verlagsbuchhandlung, Stuttgart

Endress PK (1996) Diversity and evolutionary trends in angiosperm anthers. In: D'Arcy WG, Keating RC (eds) The anther form, function and phylogeny. Cambridge University Press, Cambridge, pp 92-110

Endress P (2001a) The flowers in extant basal angiosperms and inferences on ancestral flowers. Int J Plant Sci 162(5):1111-1140

Endress PK (2001b) Origins of flower morphology. J Exp Zool 291(2):105-115. https://doi.org/10.1002/jez.1063

Endress PK, Doyle JA (2009) Reconstructing the ancestral angiosperm flower and its initial specializations. Am J Bot 96(1):22-66. https://doi.org/10.3732/ajb.0800047

Endress PK, Hufford LD (1989) The diversity of anther structures and dehiscence patterns among Magnoliidae. Bot J Linn Soc 99(4):301-346. https://doi.org/10.1111/j.1095-8339.1989.tb004 06.x

Falasca G, D'Angeli S, Biasi R, Fattorini L, Matteucci M, Canini A, Altamura MM (2013) Tapetum and middle layer control male fertility in Actinidia deliciosa. Ann Bot 112(6):1045-1055. https://doi.org/10.1093/aob/mct173

Feng X, Dickinson HG (2010) Tapetal cell fate, lineage and proliferation in the Arabidopsis anther. Development 137(14):2409-2416. https://doi.org/10.1242/dev.049320

Fernández-Gómez J, Talle B, Wilson ZA (2020) Increased expression of the MALE STERILITY1 transcription factor gene results in temperature-sensitive male sterility in barley. J Exp Bot 71(20):6328-6339. https://doi.org/10.1093/jxb/eraa382
Flores-Rentería L, Orozco-Arroyo G, Cruz-García F, García-Campusano F, Alfaro I, Vázquez-Santana S (2013) Programmed cell death promotes male sterility in the functional dioecious Opuntia stenopetala (Cactaceae). Ann Bot 112(5):789-800. https://doi. org/10.1093/aob/mct141

Furness CA, Rudall PJ (1998) The tapetum and systematics in monocotyledons. In: Bot rev 64(3) https://doi.org/10.1007/bf02856565

Furness CA, Rudall PJ (2001) The tapetum in basal angiosperms: early diversity. Int J Plant Sci 162(2):375-392. https://doi.org/10.1086/ 319580

Furness CA, Rudall PJ, Sampson FB (2002) Evolution of microsporogenesis in angiosperms. Int J Plant Sci 163(2):235-260. https:// doi.org/10.1086/338322

Gómez JF, Talle B, Wilson ZA (2015) Anther and pollen development: a conserved developmental pathway. J Integr Plant Biol 57(11):876-891. https://doi.org/10.1111/jipb.12425

Hermann PM, Palser BF (2000) Stamen development in the Ericaceae. I. Anther wall, microsporogenesis, inversion, and appendages. Am J Bot 87(7):934-957. https://doi.org/10.2307/2656993

Hernández-Cruz R, Silva-Martínez J, García-Campusano F, CruzGarcía F, Orozco-Arroyo G, Alfaro I, Vázquez-Santana S (2019) Comparative development of staminate and pistillate flowers in the dioecious cactus Opuntia robusta. Plant Reproduction 32(3):257-273. https://doi.org/10.1007/s00497-019-00365-w

Hufford LD, Endress PK (1989) The diversity of anther structures and dehiscence patterns among Hamamelididae. Bot J Linn Soc 90:301-346

Iwano M, Entani T, Shiba H, Takayama S, Isogai A (2004) Calcium crystals in the anther of petunia: the existence and biological significance in the pollination process. Plant Cell Physiol 45(1):40 47. https://doi.org/10.1093/pcp/pch004

Jansen RK, Cai Z, Raubeson LA et al (2007) Analysis of 81 genes from 64 plastid genomes resolves relationships in angiosperms and identifies genome-scale evolutionary patterns. Proc Natl Acad Sci USA 104(49):19369-19374. https://doi.org/10.1073/pnas. 0709121104

Kato H, Nishihama R, Weijers D, Kohchi T (2018) Evolution of nuclear auxin signaling: Lessons from genetic studies with basal land plants. J Exp Bot 69(2):291-301. https://doi.org/10.1093/jxb/ erx267

Kaul MLH (1988) Male Sterility in Higher Plants. Springer, Berlin. https://doi.org/10.1007/978-3-642-83139-3

Kay KM, Jogesh T, Tataru D, Akiba S (2020) Darwin's vexing contrivance: a new hypothesis for why some flowers have two kinds of anther: heteranthery in Clarkia. Proc R Soc B Biol Sci. https:// doi.org/10.1098/rspb.2020.2593rspb20202593

Keijzer CJ (1987) The processes of anther dehiscence and pollen dispersal. New Phytol 105:499-507. https://doi.org/10.1111/j.14698137.1987.tb00886.x

Kelliher T, Egger RL, Zhang H, Walbot V (2014) Unresolved issues in pre-meiotic anther development. Front Plant Sci 5:1-9. https:// doi.org/10.3389/fpls.2014.00347

Kelliher T, Walbot V (2011) Emergence and patterning of the five cell types of the Zea mays anther locule. Dev Biol 350(1):32-49. https://doi.org/10.1038/jid.2014.371

Larson BMH, Barrett SCH (1999) The pollination ecology of buzzpollinated Rhexia virginica (Melastomataceae). Am J Bot 86(4):502-511. https://doi.org/10.2307/2656811

Lau S, Shao N, Bock R, Jürgens G, De Smet I (2009) Auxin signaling in algal lineages: fact or myth? Trends Plant Sci 14(4):182-188. https://doi.org/10.1016/j.tplants.2009.01.004

Lavy M, Prigge MJ, Tao S, Shain S, Kuo A, Kirchsteiger K, Estelle M (2016) Constitutive auxin response in Physcomitrella reveals complex interactions between Aux/IAA and ARF proteins. Elife 5:1-22. https://doi.org/10.7554/eLife.13325 
Le Bail A, Billoud B, Kowalczyk N, Kowalczyk M, Gicquel M, Le Panse S, Stewart S, Scornet D, Cock JM, Ljung K, Charrier B (2010) Auxin metabolism and function in the multicellular brown alga ectocarpus siliculosus. Plant Physiol 153(1):128-144. https://doi.org/10.1104/pp.109.149708

Li HT, Yi TS, Gao LM et al (2019) Origin of angiosperms and the puzzle of the Jurassic gap. Nature Plants 5(5):461-470. https:// doi.org/10.1038/s41477-019-0421-0

Manning JC (1996) Diversity of endothecial patterns in the angiosperms. In: D'Arcy WG, Keating RC (eds) The anther form, function and phylogeny. Cambridge University Press, Cambridge, pp 136-158

Marazzi B, Conti E, Endress PK (2007) Diversity in anthers and stigmas in the buzz-pollinated genus Senna (Leguminosae, Cassiinae). Int J Plant Sci 168(4):371-391. https://doi.org/10. 1086/512105

Marciniak K, Przedniczek K (2019) Comprehensive insight into gibberellin- and jasmonate-mediated stamen development. Genes. https://doi.org/10.3390/genes10100811

Matsui T, Hasegawa T (2019) Effect of long anther dehiscence on seed set at high temperatures during flowering in rice (Oryza sativa L.). Sci Rep 9(1):3-10. https://doi.org/10.1038/ s41598-019-56792-2

Mitsuda WN, Seki M, Shinozaki K, Ohme-Takagi M, Mitsuda N, Seki M, Shinozaki K, Ohme-Takagi M (2005) The NAC transcription factors NST1 and NST2 of Arabidopsis regulate secondary wall thickenings and are required for anther dehiscence. Plant Cell 17(11):2993-3006. https://doi.org/10.1105/tpc.105. 036004

Murat F, Armero A, Pont C, Klopp C, Salse J (2017) Reconstructing the genome of the most recent common ancestor of flowering plants. Nat Genet 49(4):490-496. https://doi.org/10.1038/ng. 3813

Nagpal P, Ellis CM, Weber H, Ploense SE, Barkawi LS, Guilfoyle TJ, Hagen G, Alonso JM, Cohen JD, Farmer EE, Ecker JR, Reed JW (2005) Auxin response factors ARF6 and ARF8 promote jasmonic acid production and flower maturation. Development 132(18):4107-4118. https://doi.org/10.1242/dev.01955

Nelson MR, Band LR, Dyson RJ, Lessinnes T, Wells DM, Yang C, Everitt NM, Jensen OE, Wilson ZA (2012) A biomechanical model of anther opening reveals the roles of dehydration and secondary thickening. New Phytol 196(4):1030-1037. https:// doi.org/10.1111/j.1469-8137.2012.04329.X

Noblin X, Rojas NO, Westbrook J, Llorens C, Argentina M, Dumais J (2012) The fern sporangium: a unique catapult. Science 335(6074):1322. https://doi.org/10.1126/science.1215985

Oriani A, Scatena VL (2015) Anther wall development, microsporogenesis, and microgametogenesis in Abolboda and Orectanthe: contributions to the embryology of xyridaceae (Poales). Int $\mathrm{J}$ Plant Sci 176(4):324-332. https://doi.org/10.1086/680401

Pacini E, Franchi GG, Hesse M (1985) The tapetum: Its form, function, and possible phylogeny in Embryophyta. Plant Syst Evol 149(3-4):155-185. https://doi.org/10.1007/BF00983304

Parish A et al (2012) Tapetal development and abiotic stress: a centre of vulnerability. Funct Plant Biol 39:553-559. https://doi.org/ 10.1071/FP12090

Peñuelas M, Monte I, Schweizer F, Vallat A, Reymond P, García-Casado G, Franco-Zorrilla JM, Solano R (2019) Jasmonate-related MYC transcription factors are functionally conserved in marchantia polymorpha. Plant Cell 31(10):2491-2509. https://doi.org/ 10.1105/tpc. 18.00974

Plavskin Y, Nagashima A, Perroud PF, Hasebe M, Quatrano RS, Atwal GS, Timmermans MCP (2016) Ancient trans-acting siRNAs confer robustness and sensitivity onto the auxin response. Dev Cell 36(3):276-289. https://doi.org/10.1016/j.devcel.2016.01.010
Ren X, Xin G, Du X, Ni X, Jia G, Liu H, Hao N, Liu W (2019) Abnormal tapetum development in hermaphrodites of an androdioecious tree, Tapiscia Sinensis. Tree Physiol 40(1):108-118. https:// doi.org/10.1093/treephys/tpz080

Renner SS (1989) A survey of reproductive biology in neotropical Melastomataceae and Memecylaceae. Ann Mo Bot Gard 76:496518. https://doi.org/10.2307/2399497

Rensing SA, Lang D, Zimmer A et al (2007) The Physcomitrella genome reveals evolutionary insights into the conquest of land by plants. Science 319(5859):1. https://doi.org/10.1126/science. 1150646

Rijpkema AS, Vandenbussche M, Koes R, Heijmans K, Gerats T (2010) Variations on a theme: changes in the floral ABCs in angiosperms. Semin Cell Dev Biol 21(1):100-107. https://doi. org/10.1016/j.semcdb.2009.11.002

Rümpler F, Theißen G (2019) Reconstructing the ancestral flower of extant angiosperms: the "war of the whorls" is heating up. J Exp Bot 70(10):2615-2622. https://doi.org/10.1093/jxb/erz106

Sajo MG, Furness CA, Prychid CJ, Rudall PJ (2005) Microsporogenesis and anther development in Bromeliaceae. Grana 44(2):65-74. https://doi.org/10.1080/00173130510010503

Sajo MG, Furness CA, Rudall PJ (2009) Microsporogenesis is simultaneous in the early-divergent grass Streptochaeta, but successive in the closest grass relative Ecdeiocolea. Grana 48(1):27-37. https://doi.org/10.1080/00173130902746466

Sauquet H, Von Balthazar M, Magallón S et al (2017) The ancestral flower of angiosperms and its early diversification. Nat Commun. https://doi.org/10.1038/ncomms16047

Schnittger A, Grini PE, Folkers U, Hülskamp M (1996) Epidermal fate map of the Arabidopsis shoot meristem. Dev Biol 175(2):248255. https://doi.org/10.1006/dbio.1996.0112

Scott RJ, Spielman M, Dickinson HG (2004) Stamen structure and function. In The plant cell 16:S46-S60. https://doi.org/10.1105/ tpc. 017012

Silva CS, Puranik S, Round A, Brennich M, Jourdain A, Parcy F, Hugouvieux V, Zubieta C (2016) Evolution of the plant reproduction master regulators LFY and the MADS transcription factors: the role of protein structure in the evolutionary development of the flower. Front Plant Sci 6:1-18. https://doi.org/10.3389/ fpls.2015.01193

Sokoloff DD, Remizowa MV, Bateman RM, Rudall PJ (2018) Was the ancestral angiosperm flower whorled throughout? Am J Bot 105(1):5-15. https://doi.org/10.1002/ajb2.1003

Song S, Chen Y, Liu L, See YHB, Mao C, Gan Y, Yu H (2018) OsFTIP7 determines auxin-mediated anther dehiscence in rice. Nat Plants 4(7):495-504. https://doi.org/10.1038/ s41477-018-0175-0

Song S, Qi T, Huang H, Ren Q, Wu D, Chang C, Peng W, Liu Y, Peng J, Xie D (2011) The jasmonate-ZIM domain proteins interact with the R2R3-MYB transcription factors MYB21 and MYB24 to affect jasmonate-regulated stamen development in Arabidopsis. Plant Cell 23(3):1000-1013. https://doi.org/10.1105/tpc.111. 083089

Sztein AE, Cohen JD, Cooke TJ (2000) Evolutionary patterns in the auxin metabolism of green plants. Int J Plant Sci 161(6):849859. https://doi.org/10.1086/317566

Tanurdzic M, Banks JA (2004) Sex-determining mechanisms in land plants. Plant Cell 16:S61-S71. https://doi.org/10.1105/tpc. 016667

Taylor ML, Osborn JM (2006) Pollen ontogeny in Brasenia (Cabombaceae, Nymphaeales). Am J Bot 93(3):344-356. https://doi.org/ 10.3732/ajb.93.3.344

Theissen G, Melzer R (2007) Molecular mechanisms underlying origin and diversification of the angiosperm flower. Ann Bot 100(3):603-619. https://doi.org/10.1093/aob/mcm143 
Theißen G, Saedler H, Theissen G, Saedler H (2001) Floral quartets. Nature 409:469-471. https://doi.org/10.1111/dom.13526

Tiwari SC, Gunning BES (1986) Development and cell surface of a non-syncytial invasive tapetum inCanna: ultrastructural, freezesubstitution, cytochemical and immunofluorescence study. Protoplasma 134(1):1-16. https://doi.org/10.1007/BF01276371

Tobe H, Jaffré T, Raven PH (2000) Embryology of Amborella (Amborellaceae): descriptions and polarity of character states. J Plant Res 113(3):271-280. https://doi.org/10.1007/p100013935

Tsuzuki M, Nishihama R, Ishizaki K, Kurihara Y, Matsui M, Bowman JL, Kohchi T, Hamada T, Watanabe Y (2016) Profiling and characterization of small RNAs in the liverwort, Marchantia polymorpha, belonging to the first diverged land plants. Plant Cell Physiol 57(2):359-372. https://doi.org/10.1093/pcp/pcv182

Vallejo-MarÍn M, Manson JS, Thomson JD, Barrett SCH (2009) Division of labour within flowers: heteranthery, a floral strategy to reconcile contrasting pollen fates. J Evol Biol 22(4):828-839. https://doi.org/10.1111/j.1420-9101.2009.01693.x

Vljayaraghavan MR, Dhar U (1975) Kadsura heteroclita-microsporangium and pollen. J Arnold Arbor 56(1):176-182

Walker-Larsen J, Harder LD (2000) The evolution of staminodes in angiosperms: patterns of stamen reduction, loss, and functional re-invention. Am J Bot 87(10):1367-1384. https://doi.org/10. 2307/2656866

Wang C, Liu Y, Li SS, Han GZ (2015) Insights into the origin and evolution of the plant hormone signaling machinery. Plant Physiol 167(3):872-886. https://doi.org/10.1104/pp.114.247403

Wang Y, Ye H, Bai J, Ren F (2021) The regulatory framework of developmentally programmed cell death in floral organs: a review. Plant Physiol Biochem 158:103-112. https://doi.org/10.1016/j. plaphy.2020.11.052

Wilson ZA, Song J, Taylor B, Yang C (2011) The final split: the regulation of anther dehiscence. J Exp Bot 62(5):1633-1649. https:// doi.org/10.1093/jxb/err014

Wilson ZA, Zhang DB (2009) From arabidopsis to rice: Pathways in pollen development. J Exp Bot 60(5):1479-1492. https://doi.org/ 10.1093/jxb/erp095

Winter KU, Saedler H, Theißen G (2002) On the origin of class B floral homeotic genes: functional substitution and dominant inhibition in Arabidopsis by expression of an orthologue from the gymnosperm Gnetum. Plant J 31(4):457-475. https://doi.org/10.1046/j. 1365-313X.2002.01375.x

Yang C, Song J, Ferguson AC, Klisch D, Simpson K, Mo R, Taylor B, Mitsuda N, Wilson ZA (2017) Transcription factor MYB26 is key to spatial specificity in anther secondary thickening formation. Plant Physiol 175(1):333-350. https://doi.org/10.1104/pp. 17.00719

Yang C, Xu Z, Song J, Conner K, Vizcay Barrena G, Wilson ZA, Barrena GV, Wilson ZA (2007) Arabidopsis MYB26/MALE STERILE35 regulates secondary thickening in the endothecium and is essential for anther dehiscence. Plant Cell 19(2):534-548. https://doi.org/10.1105/tpc.106.046391

Yeung EC, Oinam GS, Yeung SS, Harry I (2011) Anther, pollen and tapetum development in safflower, Carthamus Tinctorius L. Sex Plant Reprod 24(4):307-317. https://doi.org/10.1007/ s00497-011-0168-x

Yu J, Jiang M, Guo C (2019) Crop pollen development under drought: from the phenotype to the mechanism. Int J Mol Sci 20(7):1. https://doi.org/10.3390/ijms20071550

Zhan H, Xiong H, Wang S, Yang ZN (2018) Anther Endotheciumderived very-long-chain fatty acids facilitate pollen hydration in arabidopsis. Mol Plant 11(8):1101-1104. https://doi.org/10. 1016/j.molp.2018.05.002

Zhang D, Luo X, Zhu L (2011) Cytological analysis and genetic control of rice anther development. J Genet Genomics 38(9):379-390. https://doi.org/10.1016/j.jgg.2011.08.001

Zhang D, Yang L (2014) Specification of tapetum and microsporocyte cells within the anther. Curr Opin Plant Biol. https://doi.org/10. 1016/j.pbi.2013.11.001

Zhao Z, Zhang Y, Liu X et al (2013) A role for a dioxygenase in auxin metabolism and reproductive development in rice. Dev Cell 27(1):113-122. https://doi.org/10.1016/j.devcel.2013.09.005

Zheng L, Nagpal P, Villarino G, Trinidad B, Bird L, Huang Y, Reed JW (2019) MiR167 limits anther growth to potentiate anther dehiscence. Development (cambridge). https://doi.org/10.1242/ dev. 174375

Zhu T, Li Z, An X, Long Y, Xue X, Xie K, Ma B et al (2020) Normal structure and function of endothecium chloroplasts maintained by ZmMs33-mediated lipid biosynthesis in tapetal cells are critical for anther development in maize. Mol Plant 13(11):16241643. https://doi.org/10.1016/j.molp.2020.09.013

Publisher's Note Springer Nature remains neutral with regard to jurisdictional claims in published maps and institutional affiliations. 